\title{
Análise crítica da Proposta do Constitucionalismo Popular de Kramer e da Defesa da Supremacia Judicial
}

\author{
CRITICal analysis of KRamer's Popular Constitutionalism \\ PROPOSAL AND DEFENSE OF JUDICIAL SUPREMACY
}

\begin{abstract}
Lara Bonemer Rocha Floriani
Doutora em Direito Econômico e Desenvolvimento na Pontificia Universidade Católica do Paraná (Bolsista FA/CAPES). Mestra em Direito Econômico e Socioambiental pela PUCPR (Bolsista CNPQ). Professora no curso de graduação em Direito da Faculdade Estácio e do Centro Universitário Unibrasil.

Coordenadora da Pós-graduação em Direito Econômico da PUC-PR e Advogada. ORCID: [orcid.org/0000-0002-8112-0949]. lara@rochaefloriani.com.br
\end{abstract}

\section{Claudia Maria Barbosa}

Professora titular de direito constitucional da Pontificia Universidade Católica do Paraná, onde leciona e dirigiu os cursos de graduação, mestrado e doutorado. Desenvolveu em 2019 um estudo de pós-doutoramento na Universidade de Coimbra, Portugal, e previamente já havia conduzido uma investigação em pós-doutorado na York University, Toronto, Canadá. Doutora, Mestre e Graduada em Direito pela Universidade Federal de Santa Catarina, com pesquisa em sistemas juridicos comparados desenvolvida na Universidade de Montreal, Canadá. É Bolsista "Produtividade em Pesquisa" do CNPq. ORCID: [orcid.org/0000-0002-7055-9403]. claudia.mr.barbosa@gmail.com

Recebido em: 05.05.2021

Aprovado em: 10.06 .2021 DOI: [doi.org/10.48143/rdai.18.lbrf].

\section{ÁreAS do DIREITo: Administrativo; Constitucional}

Resumo: 0 constitucionalismo popular surge como uma contraposição ao constitucionalismo liberal, ao rejeitar a supremacia do Poder Judiciário e propor a transferência da autoridade interpretativa, final e vinculante da Suprema Corte para o povo. A teoria, que teve sua manifestação mais expoente na obra de Larry Kramer, se funda em uma insatisfação popular com o modelo
ABstract: Popular constitutionalism arises as a counterpoint to liberal constitutionalism, by rejecting the supremacy of the Judicial Power and proposing the transfer of the final, binding, interpretative authority of the Supreme Court to the people. The theory, which had its most prominent manifestation in Larry Kramer's work, is based on a popular dissatisfaction with the current 
constitucional vigente e na perspectiva de que o povo é o melhor intérprete para preservar o real sentido do texto constitucional. Contudo, a proposta, de acordo com a visão defendida no presente trabalho, parte de pressupostos equivocados, afetando, sobremaneira, sua subsistência e implementação no plano prático. Neste artigo, fazendo-se uso do método hipotético-dedutivo, é analisada a teoria do constitucionalismo popular, seguida das criticas desenvolvidas sob 0 aspecto conceitual e das bases fundamentais da proposta de Larry Kramer. A análise revela que Kramer, procurando prevenir a tirania judicial, defende a proposta do constitucionalismo popular, enquanto as criticas se direcionam no sentido de que a fragilidade da supremacia judicial abre espaço para uma tirania popular. Soluções para esse dilema são decididas, contudo, na Politica, e não no Direito.

Palavras-chave: Constitucionalismo popular Supremacia judicial - Tirania. constitutional model and on the perspective that the people are the best interpreter to preserve the real meaning of the constitutional text. However, according to the perspective adopted in this paper, the proposal starts from mistaken assumptions, affecting, in particular, their subsistence and practical implementation. In this article, using the hypothetico-deductive method, the theory of popular constitutionalism is analyzed, followed by the criticisms developed under the conceptual aspect and the fundamental bases of the proposal of Larry Kramer. The analysis reveals that Kramer, seeking to prevent judicial tyranny, defends the proposal of popular constitutionalism, while the criticisms are directed in the sense that the fragility of the judicial supremacy gives room for a popular tyranny. However, solutions to this dilemma are decided in politics, not law.

KeYwords: Federal Constitution - Popular constitutionalism - Judicial supremacy - Accountability.

SUMÁRIO: 1. Introdução. 2. Sintese do constitucionalismo popular na visão de Larry Kramer. 3. Criticas à teoria do constitucionalismo popular: Imprecisão conceitual e inexistência de ferramentais para implementação no plano prático. 4. Poder, autoridade e supremacia judicial. 5. Porque, então, a supremacia judicial?. 6. Considerações finais. 7. Referências.

\section{INTRODUÇÃO}

O constitucionalismo popular surge como uma proposta de se contrapor ao constitucionalismo liberal, fundado na rigidez constitucional e na supremacia judicial, na medida que atribuiu ao Poder Judiciário a função interpretativa em caráter final e vinculante, do real sentido do texto constitucional. A teoria, fortemente influenciada pelas constituições sociais, inaugura a proposta de retira$\mathrm{da}$, ainda que não totalmente, em algumas vertentes, da supremacia das cortes superiores para a interpretação da Constituição, permitindo ao povo a atuação na condição de intérprete final. Seu contexto de surgimento é influenciado por um cenário de judicialização da política, ativismo judicial e abusos na interpretação da Constituição. Tem-se Supremas Cortes sobrecarregadas com matérias que, muitas vezes, não incumbem à sua competência e decisões que extrapolam, 
supremacia judicial e em seu fundamento último, proteger a Constituição e os cidadãos de maiorias eventuais e clamor popular. O quadro em que esse paradoxo se desenvolve, contudo, deveria encontrar limites na discricionariedade judicial e na preocupação em assegurar condições procedimentais e materiais na deliberação fundada em igual respeito e consideração. Fora desses limites verifica-se a tirania judicial. O risco dessa tirania é o que Kramer procura prevenir com a proposta do constitucionalismo popular, enquanto as críticas apontadas temem, por seu turno, que a fragilidade da supremacia judicial dê espaço a uma tirania popular. Soluções para esse dilema, contudo, decidem-se na Política, não no Direito.

\section{REFERÊNCIAS}

ALEXANDER, Larry; SOLUM, Lawrence B. Popular? Constitutionalism? Harvard Law Review. Mar. 2005. Disponível em: [papers.ssrn.com/sol3/papers. cfm?abstract_id=692224]. Acesso em: 15.07.2020.

AMAR, Akhil; HIRSCH, Alan. For the People: What the Constitution Really Says About Your Rights. New York: Simon \&Schuster, 1998.

BRANDÃO, Rodrigo. SupremaciaJudicial versus Diálogos Constitucionais. A quem cabe a última palavra sobre o sentido da Constituição? Rio de Janeiro: Lumem Iuris, 2017.

CHEMERINSKY, Erwin. In Defense of Judicial Supremacy, 58. Wm. \& Mary L. Rev. 1459 (2020). Disponível em: [scholarship.law.berkeley.edu/facpubs/2796]. Acesso em: 15.07.2020.

DWORKIN, Ronald. Levando os direitos a sério. São Pauto: Martins Fontes, 2002.

ELY, John Hart. Democracy and distrust. Fourteenth printing. Cambridge: Harvard University Press, 2002.

GODOY, Miguel Gualano de. Devolver a constituiçâa ao povo: crítica à supremacia judicial e diálogos interinstitucionais. Tese, UFPR, Curitiba, 2015,

JARAMILLO, Leonardo García. Introducción. In: Constitucionalismo democrático: por una reconciliación entre constitución y Pueblo. Trad. Leonardo García Jaramillo. Buenos Aires: Siglo Veintiuno Editores S.A., 2013. p. 11-29.

KRAMER, Larry D. The people themselves: popular constitutionalism and Judicial review. New York: Oxford University Press. 2004.

LIMA, Gabriela Carneiro de Albuquerque Basto. A tensão entre o Povo e as Cortes: a escolha do constitucionalismo popular. Dissertação, USP, São Paulo, 2014.

MARSHALL, John. Decisões constitucionais. Rio de Janeiro: Imprensa Nacional, 1908.

PARKER, Richard. Here, The People Rule: A Constitutional Populist Manifesto. Cambridge: Harvard University Press, 1994. 
POST, Robert e SIEGEL, Reva. Constitucionalismo democrático. In: Constitucionalismo democrático: por una reconciliación entre constitución y Pueblo. Trad. Leonardo García Jaramillo. Buenos Aires: Siglo Veintiuno Editores S.A., 2013. TUSHNET, MARK V. Popular Constitutionalism as Political Law. Georgetown Law. Constitutional Commons, 2006. Disponível em: [scholarship.law.georgetown.edu/facpub/233]. Acesso em: 15.07.2020.

\section{PESQUisas do EDITORIAL}

\section{Veja também Doutrinas relacionadas ao tema}

- A supremacia judicial no Brasil: sofisma ou paralogismo?, de Miguel Gualano de Godoy - RPC 10/255-277 (DTR|2019|42372);

- Neoconstitucionalismo e Constitucionalização do Direito (o triunfo tardio do Direito Constitucional no Brasil), de Luis Roberto Barroso - RDCl 7/533-584 (DTR|2015|11002);

- Os diálogos institucionais como ferramenta de garantia do equilibrio entre os poderes estatais: o risco de uma postura ativista do Supremo Tribunal, de Bruna Pereira Aquino e Américo Bedê Freire Júnior - RDCl 107/35-59 (DTR|2018|15581); $\mathrm{e}$

- Os intérpretes da Constituição após seus 30 anos: a necessidade de uma nova hermenêutica constitucional democrática, de Flávio Martins - RT 996/97-114 (DTR|2018|19918). 